\title{
Safety of Paracetamol in Osteoarthritis: What Does the Literature Say?
}

\author{
Philip G. Conaghan ${ }^{1}\left[\right.$ Nigel Arden ${ }^{2,3} \cdot$ Bernard Avouac $^{4} \cdot$ Alberto Migliore $^{5} \cdot$ René Rizzoli $^{6,7}$
}

(c) The Author(s) 2019

\begin{abstract}
Osteoarthritis (OA) is a major cause of pain and physical disability in adults, and an increasingly common disease given its associations with aging and a growing obese/overweight population. Paracetamol is widely recommended for analgesia at an early stage in the management of $\mathrm{OA}$, and, although frequently prescribed, evidence suggests the efficacy of paracetamol for OA pain is low. Furthermore, there have been recent concerns over the safety profile of paracetamol, with reports of gastrointestinal, cardiovascular, hepatic and renal adverse events. This narrative review summarizes recent literature on the benefits and harms of paracetamol for OA pain. Data on long-term paracetamol safety are derived largely from observational evidence, and are difficult to interpret given the potential biases of such data. Nonetheless, a considerable degree of toxicity is associated with paracetamol use among the general population, especially at the upper end of standard analgesic doses. Paracetamol is linked to liver function abnormalities and there is evidence for liver failure associated with non-intentional paracetamol overdose. Safety data for paracetamol use in the older population (aged $>65$ years) are sparse; however, there is some evidence that frail elderly people may have impaired paracetamol clearance. Given that the analgesic benefit of paracetamol in OA joint pain is uncertain and potential safety issues have been raised, more careful consideration of its use is required.
\end{abstract}

\section{Introduction}

Osteoarthritis (OA) is a major cause of pain in adults [1]. Pain associated with OA of the hip and knee results in increased physical and walking disability, which increases the risk of all-cause mortality [2]. OA is an increasingly common disease given its associations with aging and a growing obese/overweight population, with symptomatic knee OA affecting more than 250 million older people ( $>50$ years) worldwide [3]. Paracetamol (acetaminophen), discovered over 140 years ago, is still one of the most commonly

Philip G. Conaghan

p.conaghan@leeds.ac.uk

Nigel Arden

nigel.arden@ndorms.ox.ac.uk

Bernard Avouac

bernardavouac@sfr.fr

Alberto Migliore

migliore.alberto60@gmail.com

René Rizzoli

Rene.Rizzoli@unige.ch

1 Leeds Institute of Rheumatic and Musculoskeletal Medicine, University of Leeds and NIHR Leeds Biomedical Research Centre, Leeds Teaching Hospitals NHS Trust, Leeds, UK used analgesic and antipyretic medications across the world, and is included on the World Health Organization's List of Essential Medicines, the most effective and safe medicines needed in a health system $[4,5]$. The management of pain in OA is based on a combination of pharmacologic and nonpharmacologic approaches, with paracetamol commonly recommended for analgesia at an early step in treatment recommendations [6-9]. Use is often driven by an absence of therapeutic alternatives, especially given the safety profile of non-steroidal anti-inflammatory drugs (NSAIDs) and opioids. Each year in the US, approximately $6 \%$ of adults are prescribed paracetamol doses of more than $4 \mathrm{~g} /$ day,

2 MRC Lifecourse Epidemiology Unit, University of Southampton, Southampton General Hospital, Southampton, UK

3 Arthritis Research UK Centre for Sport, Exercise and Osteoarthritis, University of Oxford, Oxford, UK

4 Department of Public Health, Epidemiology and Health Economics, University of Liège, Liège, Belgium

5 Unit of Rheumatology, San Pietro Fatebenefratelli Hospital, Rome, Italy

6 Division of Bone Diseases, Geneva University Hospitals and Faculty of Medicine, Geneva, Switzerland

7 WHO Collaborating Centre for Public Health Aspects of Musculoskeletal Health and Aging, Liège, Belgium 


\section{Key Points}

Paracetamol is widely used for analgesia in osteoarthritis despite reported low efficacy, with use largely driven by a lack of effective or tolerated alternative treatments, and its relative safety.

However, there is some evidence demonstrating gastrointestinal, cardiovascular, hepatic and renal toxicity with paracetamol, perhaps reflecting populations that use this drug, but requiring further investigation.

Although paracetamol remains safer than some alternative therapies, such as non-steroidal anti-inflammatory drugs, paracetamol should be used carefully, particularly for chronic pain management.

and 30,000 patients are hospitalized for paracetamol toxicity [10]. Although traditionally considered safe, in recent years, a steady increase in the number of registered cases of paracetamol-induced liver toxicity has been observed worldwide [4]. Although older patients are among the highest users of analgesic medications for musculoskeletal pain, there is limited clinical evidence to inform on the safe and effective use of these medications in the elderly population [11]. A review of 83 clinical trials involving $>10,000$ subjects treated with simple analgesics found that only $2.3 \%$ of people were aged over 65 years [12]. This narrative literature review aims to describe the use, efficacy and toxicity associated with chronic use of paracetamol for OA pain. Given the paucity of long-term randomized controlled trials (RCTs), safety data from observational, cohort studies were also considered.

\section{The Use of Paracetamol in Osteoarthritis (OA)}

Paracetamol is frequently prescribed for analgesia. Among participants in the USA Osteoarthritis Initiative (OAI), over $80 \%$ reported using medication for knee pain in the previous 12 months, and $70 \%$ had used a conventional analgesic or nutraceutical for more than half of the days of the month, of which paracetamol was taken by $14 \%$ of participants [13]. The 2011 National Health and Wellness Survey (NHWS) collected information on 57,512 adults (aged $\geq 18$ years) from the general population of five EU countries. Among people with self-reported peripheral joint OA ( $n=3750$; mostly aged 55-74 years), nearly half (47\%) reported prescription medication use, $27 \%$ reported use of over-the-counter (OTC) medications, and $9 \%$ of patients used both. The prescription of paracetamol was variable, ranging from $0 \%$ in Germany up to $6 \%$ in Spain, while the use of prescription NSAIDs was highest in Germany $(82 \%)$ and lowest in France (47\%). However, OTC medication use was reported by $15-30 \%$ of people [14], and paracetamol was likely included in this OTC use. Variation in the use of pharmacotherapy for OA between countries may be driven by national prescribing guidelines and health system economics (for example, in countries where costs of medical consultation and prescription outweigh the OTC price for paracetamol, prescription may be low). Of the prescription medications, respondents had been using paracetamol for the longest duration (mean 84 months) and for 21 days of the last month [14]. A prospective cohort study of analgesic prescribing to older people (aged $>75$ years; $N=149$ ) by general practitioners in France found that pain was largely due to OA, and, among those receiving at least one analgesic $(66 \%)$, almost all received paracetamol (>96\%), which is in line with national prescribing guidance [15].

Despite the availability of analgesics, inadequate pain relief is common among patients with knee OA and is associated with large functional loss and impaired quality of life. In an observational study of real-world therapies for OA, after $\geq 2$ weeks of physician-prescribed treatment, more than half of patients with knee OA reported inadequate pain relief defined as moderate to severe pain [16]. The most commonly prescribed analgesic medications were NSAIDs (60\% of patients), followed by paracetamol (44\%) and opioid-containing medications (27\%).

Chronic multiple-site joint pain (MSJP) is common in older people and is associated with poor outcomes. MSJP represents a combination of OA, back pain and soft tissue disorders; muscle weakness is extremely common [17]. In a cohort of MSJP patients, concurrent pharmacological therapies were used by $47 \%$. Paracetamol was used by $62 \%$ of patients (38\% on prescription) and $23 \%$ regularly used paracetamol. Among the $26 \%$ of MSJP patients who had previously stopped taking paracetamol, $98 \%$ reported stopping due to inefficacy or a loss of efficacy [17].

\section{Paracetamol Efficacy in OA}

Although widely used as a first-line analgesic in OA, there are increasing doubts, from recent meta-analyses, regarding the analgesic efficacy of paracetamol. A Cochrane review on paracetamol in OA, performed over a decade ago, found a significantly superior reduction in pain compared with placebo from seven RCTs, albeit with a small effect size (ES; standardized mean difference [SMD] - 0.14, 95\% confidence interval [CI] -0.23 to -0.05$)$ [18]. In a subsequent analysis adjusting for trial quality, when the five high-quality, placebo-controlled RCTs were considered in isolation 
(Jadad score $=5)$, the ES of paracetamol on pain was even smaller (ES $0.10,95 \%$ CI - 0.03 to 0.23 ) [19]. This analysis also suggested that paracetamol had no significant effect on stiffness (ES $0.16,95 \% \mathrm{CI}-0.05$ to 0.37 ) or physical function (ES $0.09,95 \% \mathrm{CI}-0.03$ to 0.22 ) [19].

In a recent systematic review and meta-analysis, paracetamol was found to provide minimal short-term benefit for people with OA [20]. For hip or knee OA, there was 'high quality' evidence that paracetamol provided a significant, although not clinically important, effect on pain (weighted mean difference [WMD] $-3.7,95 \% \mathrm{CI}-5.5$ to -1.9$)$ and disability (WMD $-2.9,95 \% \mathrm{CI}-4.9$ to -0.9$)$ in the short term $(>2$ weeks and $\leq 3$ months). In the immediate term ( $\leq 2$ weeks), the effect of paracetamol on pain was lower (WMD - 3.3, 95\% CI -5.8 to -0.8 ), with no immediate effect on function (WMD - $1.7,95 \% \mathrm{CI}-6.0$ to 2.6 ). In a 2017 network meta-analysis of analgesic medications for the management of pain in knee and hip OA, the authors concluded, on the basis of the available data, that there is no role for single-agent paracetamol in the treatment of OA patients irrespective of dose [21].

A recent meta-analysis focusing on the long-term efficacy of pharmacotherapy for OA [22], identified only one RCT of $>12$ months' duration that included paracetamol (650 mg, four times daily) in comparison with naproxen (375 mg, twice daily) [23]. The study found similar efficacy between paracetamol and naproxen among patients who completed the 2-year study ( $n=27 / 88$ with paracetamol and $n=35 / 90$ with naproxen), although a very high withdrawal rate was observed. Withdrawal due to lack of drug efficacy was more frequent for paracetamol (22\%) compared with naproxen (16\%), with withdrawal due to adverse drug reactions common in both groups, although slightly higher for the NSAID (18\% with paracetamol and $23 \%$ with naproxen) [23].

\section{Paracetamol Safety}

Paracetamol is generally considered to be safer than other commonly used analgesics such as NSAIDs or opiates. However, a recent systematic literature review of observational studies (given an absence of long-term trials) reported a considerable degree of toxicity associated with paracetamol use among the general adult population, especially at the upper end of standard analgesic doses [24]. A striking trend of dose-response was observed between paracetamol at standard analgesic doses and adverse events (AEs) that are often observed with NSAIDs, including an increasing incidence of mortality, cardiovascular, gastrointestinal (GI) and renal AEs in the general population. Eight cohort studies met the inclusion criteria and investigated one or more of the AEs of interest, with oral doses of paracetamol 0.5-1.0 g every $4-6 \mathrm{~h}$ to a maximum of $4.0 \mathrm{~g} /$ day [24]. Two of the studies included in this analysis reported on mortality, of which one reported a dose-response increase in all-cause mortality and rate of GI AEs or bleeds based on the low to high medication possession ratio (measured by repeat prescription frequency) (Table 1) [25]. The other study reported an increase in standardized mortality ratio for patients prescribed paracetamol compared with those not prescribed paracetamol, regardless of the specific cause of death, with a nearly doubled overall death rate [26]. Four studies included in the meta-analysis showed a dose-response relationship with risk of cardiovascular AEs. One study reported an increasing risk ratio of all cardiovascular AEs based on dosing frequency (Table 1), and three studies included in the meta-analysis reported on the risk of renal AEs with paracetamol, with one study reporting a dose-ranging increase in odds ratio (OR) based on cumulative intake and measured as a $\geq 30 \%$ decrease in estimated glomerular filtration rate (eGFR), ranging from 1.80 with up to $500 \mathrm{~g}$ in a lifetime (95\% CI 1.02-3.18) to 2.04 with $>3000 \mathrm{~g}(95 \%$ CI 1.28-3.25) [27].

\subsection{Cardiovascular/Cerebrovascular Adverse Events (AEs)}

\subsubsection{Hypertension}

Concomitant paracetamol can adversely affect the efficacy of antihypertensive therapy (with ramipril or valsartan) [28]. In a double-blind crossover trial, 174 hypertensive patients with OA were treated with antihypertensives for 8 weeks. Of those patients, 135 with normalized blood pressure were randomized to naproxen or paracetamol for 2 weeks. Naproxen significantly increased clinic and ambulatory systolic/ diastolic blood pressure in patients treated with ramipril or valsartan $(p<0.05)$, but not aliskiren. Paracetamol slightly but significantly affected clinic and ambulatory blood pressure in all three groups and also produced a small but significant increase in heart rate $(p<0.05)$.

This study cannot account for individual pain over the study period, and pain can drive hypertension. Nevertheless, when paracetamol is chosen for OA management in subjects with hypertension, patients should be evaluated as carefully as when traditional NSAIDs are administered.

\subsubsection{Acute Myocardial Infarction}

The risk of non-fatal acute myocardial infarction (AMI) associated with traditional NSAIDs, non-narcotic analgesics (paracetamol and metamizole), and symptomatic slow-acting drugs in OA (SYSADOAs) was assessed in a Spanish primary care database study of case-control design ( cases $=3833$, controls $=20,000)$ [29]. The greatest risk of non-fatal AMI occurred with high background cardiovascular risk patients and long use of traditional NSAIDs (> 365 
Table 1 Increased risk of adverse outcomes with frequent paracetamol dosing

\begin{tabular}{|c|c|c|c|c|}
\hline Adverse outcomes & Repeat use, low MPR & Repeat use, medium MPR & Repeat use, high MPR & Repeat use, very high MPR \\
\hline $\begin{array}{l}\text { All-cause mortality }{ }^{\mathrm{a}}[\mathrm{RR}(95 \% \mathrm{CI})] \\
{[25]}\end{array}$ & $0.95(0.92-0.98)$ & $1.08(1.05-1.11)$ & $1.27(1.21-1.33)$ & $1.63(1.58-1.68)$ \\
\hline \multirow{2}{*}{$\begin{array}{l}\text { Gastrointestinal } \mathrm{AEs}^{\mathrm{b}}[\mathrm{RR}(95 \% \mathrm{CI})] \\
{[25]}\end{array}$} & $1.11(1.04-1.18)$ & $1.25(1.12-1.40)$ & $1.49(1.29-1.72)$ & $1.49(1.34-1.66)$ \\
\hline & PCM 1 day/week & PCM 2-3 days/week & PCM 4-5 days/week & PCM 6-7 days/week \\
\hline $\begin{array}{l}\text { Cardiovascular } \mathrm{AEs}^{\mathrm{c}} \text { [risk ratio } \\
(95 \% \mathrm{CI})][42]\end{array}$ & $0.94(0.62-1.43)$ & $1.23(0.94-1.61)$ & $1.49(0.99-2.24)$ & $1.50(1.10-2.05)$ \\
\hline
\end{tabular}

Data compiled from Roberts et al. [24]

AEs adverse events, $C I$ confidence interval, $I V$ instrumental variables, MPR medication possession ratio (based on repeat prescription frequency), $P C M$ paracetamol, $R R$ relative risk

${ }^{\mathrm{a}} \mathrm{The} \mathrm{RR}$ (IV, fixed) of all-cause mortality in patients taking paracetamol versus patients not taking paracetamol

${ }^{\mathrm{b}}$ The RR (IV, fixed) of upper gastrointestinal AEs (gastroduodenal ulcers, and complications such as upper gastrointestinal haemorrhages) in patients taking paracetamol versus patients not taking paracetamol

${ }^{\mathrm{c}}$ The risk ratio (IV, fixed) of cardiovascular AEs (confirmed or probable non-fatal myocardial infarction, non-fatal stroke, fatal coronary heart disease or fatal stroke) in patients taking paracetamol versus patients not taking paracetamol

days) (OR 1.80, 95\% CI 1.26-2.58). Paracetamol (OR 0.84, 95\% CI 0.74-0.95), glucosamine and chondroitin (OR 0.68, 95\% CI 0.47-0.99) were not associated with increased risk.

\subsubsection{Stroke}

The risk of non-fatal ischaemic stroke associated with NSAIDs and paracetamol was assessed in a Spanish population-based, case-control study (cases $=2888$, controls $=20,000)[30]$. No increased risk was found with paracetamol (OR $0.97,95 \%$ CI $0.85-1.10$ ) or glucosamine and chondroitin (OR 0.94, 95\% CI 0.67-1.33), and no increased risk was observed with traditional NSAIDs as a group (OR 1.03, 95\% CI 0.90-1.19). Not surprisingly, there was an increased risk with diclofenac (OR 1.53; 95\% CI 1.19-1.97), especially with high doses over long-term periods ( $>365$ days) and in patients with high background cardiovascular risk.

\subsection{Gastrointestinal (GI) AEs}

In the past, paracetamol was considered to be without GI toxicity, however some studies suggest an increase in GI $\mathrm{AE}$ rates with paracetamol use. Two RCTs found the overall rate of GI AEs (most commonly nausea, abdominal pain and dyspepsia) with paracetamol to be similar to that found with ibuprofen, i.e. $9 \%$ and $13 \%$, respectively [31], and $13 \%$ and $12 \%$, respectively $[32,33]$. Using patient data from the UK General Practice Research Database (GPRD), an association between paracetamol use and risk of symptomatic ulcer has been found versus non-use (relative risk 1.9, 95\% CI 1.5-2.3) [34]. A nested case-control study from the UK population compared analgesic use in 2105 cases of upper GI bleeding/perforations versus 11,500 age- and sex-matched controls (aged 40-79 years) and found an elevated risk of upper GI complications with paracetamol compared with controls (relative risk [RR] 1.3, 95\% CI 1.1-1.5), which increased to more than threefold elevated risk among those talking paracetamol at doses $>2$ g/day (RR 3.6, 95\% CI 2.6-5.1) [35].

\subsubsection{GI Hospitalization}

The rates of hospitalization for GI disorders (ulceration, perforation, or bleeding in the upper or lower GI tract) among elderly patients ( $\geq 65$ years) taking traditional NSAIDs, or the combination of a traditional NSAID and paracetamol with and without a proton pump inhibitor (PPI) versus those taking paracetamol alone, were assessed among a Canadian population-based retrospective cohort study [36]. The study found that for elderly patients requiring analgesic/anti-inflammatory treatment, use of the combination of a traditional NSAID and paracetamol may increase the risk of GI bleeding compared with either agent alone. Among the cohort of 644,183 elderly patients, there were 1854 GI hospitalizations. The rate of GI hospitalization was twice as high when an NSAID and paracetamol were used together (with or without a PPI) (Table 2). Patients with OA or rheumatoid arthritis diagnoses ( $n=115,305,18 \%$ of cohort) had a higher risk of GI events with paracetamol $>3 \mathrm{~g} /$ day compared with the main cohort (hazard ratio [HR] 1.42, 95\% CI 1.04-1.93).

\subsection{Severe Acute Liver Injury}

Paracetamol is a dose-dependent hepatotoxin, and excessive doses may lead to irreversible acute liver failure [37]. Glucuronidation and sulfation are the major metabolic pathways (phase II) for paracetamol metabolism, which become 
Table 2 Rate of gastrointestinal hospitalization among an elderly population-based cohort taking paracetamol, traditional NSAIDs, and PPIs

\begin{tabular}{|c|c|c|c|c|c|c|}
\hline & \multicolumn{3}{|l|}{ Non-users of PPIs } & \multicolumn{3}{|l|}{ Users of PPIs } \\
\hline & \multicolumn{2}{|l|}{ Drug exposure } & \multirow{2}{*}{$\begin{array}{l}\text { Upper/lower GI } \\
\text { hospitalization } \\
\text { HR }(95 \% \text { CI })\end{array}$} & \multicolumn{2}{|l|}{ Drug exposure } & \multirow{2}{*}{$\begin{array}{l}\text { Upper/lower GI } \\
\text { hospitalization } \\
\text { HR }(95 \% \mathrm{CI})\end{array}$} \\
\hline & No. of prescriptions & $\begin{array}{l}\text { Total dura- } \\
\text { tion (years) }\end{array}$ & & No. of prescriptions & $\begin{array}{l}\text { Total dura- } \\
\text { tion (years) }\end{array}$ & \\
\hline Paracetamol $\leq 3 \mathrm{~g} /$ day & $2,609,232$ & 150,364 & Reference (1.00) & $1,032,269$ & 58,344 & $0.95(0.81-1.11)$ \\
\hline Paracetamol $\geq 3 \mathrm{~g} /$ day & $1,092,891$ & 47,764 & $1.20(1.03-1.40)$ & 504,943 & 23,188 & $1.16(0.94-1.43)$ \\
\hline Paracetamol and NSAIDs & 117,914 & 7858 & $2.55(1.98-3.28)$ & 40,800 & 2666 & $2.15(1.35-3.40)$ \\
\hline NSAIDs & $1,463,323$ & 91,379 & $1.63(1.44-1.85)$ & 315,238 & 19,839 & $1.07(0.82-1.39)$ \\
\hline
\end{tabular}

The rates of hospitalization for GI disorders (ulceration, perforation, or bleeding in the upper or lower GI tract) among elderly patients ( $\geq 65$ years) taking traditional NSAIDs or the combination of a traditional NSAID and paracetamol, with and without a PPI, are compared with the rate for paracetamol alone ( $\leq 3 \mathrm{~g} /$ day) in a Canadian population-based retrospective cohort study $(N=644,183)$

Data compiled from Rahme et al. [36]

CI confidence interval, GI gastrointestinal, HR hazard ratio, NSAIDs non-steroidal anti-inflammatory drugs, PPIs proton pump inhibitors

saturated after paracetamol overdose, causing a shift to phase I metabolism and formation of a toxic metabolite that depletes glutathione and triggers mitochondrial dysfunction, resulting in cellular necrosis [38]. A number of studies have investigated the pharmacokinetics of paracetamol in healthy older adults, reporting variable effects of age [11]. General health state appears to have a greater effect on paracetamol clearance than age. Although preserved in healthy older adults, clearance to paracetamol glucuronide was markedly reduced in frail elderly patients when compared with fit subjects [39].

Three trials have evaluated the results of liver function tests to detect AEs with paracetamol (alanine aminotransferase $[\mathrm{ALT}]$ and/or aspartate aminotransferase [AST]) in participants with OA, where an abnormal test was defined as hepatic enzyme activity 1.5 times the upper limit of normal. Participants taking paracetamol in the management of spinal pain and OA of the hip or knee were nearly fourfold more likely to have abnormal results on liver function tests than participants taking placebo (WMD 3.8, 95\% CI 1.9-7.4) [20].

Acute drug overdose with paracetamol may cause acute liver failure leading to transplantation (ALFT). Overdose ALFT in Europe was evaluated in the Study of Acute Liver Transplantation (SALT) [40]. Overall, 600 cases of ALFT were identified in 52 transplant centres, of which paracetamol overdose, even without suicidal intent, was responsible for $20 \%$ of cases. Among 301 ALFT cases without clinical aetiology, 81 (27\%) were exposed to paracetamol but without overdose in the prior 30 days. When non-overdose paracetamol-associated ALFTs were considered, the event rates were very similar, between 2.6 and 4.1 (mean 3.3 ) cases per million treatment-years of paracetamol sold (Table 3), with no difference between countries.

Paracetamol poisoning is the major cause of severe acute hepatotoxicity in the UK. In a single-centre cohort study from the Scottish Liver Transplantation Unit, the clinical impact of staggered overdoses and delayed presentation following paracetamol overdose were examined [41]. The study found that 'staggered' paracetamol overdoses (repeated supratherapeutic ingestions of paracetamol), frequently taken to relieve pain, are strongly associated with reduced survival compared with single time-point overdose [41]. From the 938 cases of severe acute liver injury admitted over a period of 16 years (1992-2008), 663 (70.7\%) were due to paracetamol-induced hepatotoxicity, and 161 (24.3\%) had taken a 'staggered' paracetamol overdose compared with a single time-point overdose. Staggered overdose pattern was associated with older age and chronic alcohol abuse (a potential enhancer of paracetamol hepatotoxicity), resulting in worse clinical outcomes than single time-point paracetamol overdose. Relief of pain $(58.2 \%)$ was the most common rationale for repeated supratherapeutic ingestion, and musculoskeletal pain was the third most common reason for staggered overdose (14.3\%). Despite lower total ingested paracetamol doses and lower admission serum ALT, staggered overdose patients were more likely to be encephalopathic on admission, require renal replacement therapy or mechanical ventilation, and had higher mortality rates compared with single time-point overdoses $(37.3 \%$ vs. $27.8 \%$; $p=0.025)$. These patients are at increased risk of developing multi-organ failure. 
Table 3 Non-overdose acute liver failure leading to transplantation with exposure to paracetamol within 30 days before the first symptoms

\begin{tabular}{lccl}
\hline Country & $\begin{array}{l}\text { Non-overdose } \\
\text { ALFT }\end{array}$ & MTTY & ALFT/MTTY (95\% CI) \\
\hline France & 49 & 13.2 & $3.72(2.75-4.91)$ \\
Ireland & 1 & 0.38 & $2.63(0.08-14.7)$ \\
Italy & 4 & 1.41 & $2.84(0.77-7.26)$ \\
Netherlands & 3 & 0.73 & $4.10(0.62-8.77)$ \\
UK & 24 & 8.25 & $2.91(1.86-4.33)$ \\
All & 81 & 24.3 & $3.33(2.65-4.14)$ \\
\hline
\end{tabular}

Event rates for non-overdose paracetamol-associated ALFTs by country; mean 3.5 cases per million treatment-years of paracetamol sold. Non-overdose was defined as exposure to drugs without demonstrated overdose within 30 days prior to the index date

Reproduced from Gulmez et al. [40]. Copyright permission granted by John Wiley \& Sons, 2019

$A L F T$ acute liver failure leading to registration for transplantation, $C I$ confidence interval, MTTY million treatment-years sold

${ }^{a}$ Includes Portugal and Greece, with no cases

\section{Conclusions}

There is a rapidly increasing OA burden in an aging and increasingly overweight/obese society. Although paracetamol is commonly used for analgesia in OA, the efficacy of paracetamol overall is poor and its use is driven by belief in its relative safety and by a lack of effective or tolerated alternative pharmacotherapies. Given that people with chronic pain may use paracetamol over many years, the only relevant safety data derives from observational studies with their attendant problems, including selection bias (participants not randomly selected) and information bias (inaccurate recording of OTC medications for example, some of which may be NSAIDs). Currently, this observational evidence suggests an increased risk of AEs with paracetamol, although the data are difficult to interpret, and paracetamol remains safer than NSAIDs. Liver function abnormalities are not uncommon with paracetamol, and accidental overdose with supratherapeutic doses of paracetamol for pain is an important issue. The true risk of paracetamol use may be higher than is currently perceived in the clinical community. In this context, while the analgesic benefit of paracetamol in OA joint pain is uncertain, more careful consideration of its use is required.

Acknowledgements This paper was written on behalf of the European Society for Clinical and Economic Aspects of Osteoporosis, Osteoarthritis and Musculoskeletal Diseases (ESCEO) Working Group on the safety of anti-OA medications: Nasser Al-Daghri, Nigel Arden, Bernard Avouac, Olivier Bruyère, Roland Chapurlat, Philip Conaghan, Cyrus Cooper, Elizabeth Curtis, Elaine Dennison, Nicholas Fuggle, Gabriel Herrero-Beaumont, Germain Honvo, Margreet Kloppenburg,
Stefania Maggi, Tim McAlindon, Alberto Migliore, Ouafa Mkinsi, François Rannou, Jean-Yves Reginster, René Rizzoli, Roland Roth, Thierry Thomas, Daniel Uebelhart, and Nicola Veronese. Philip G. Conaghan is supported in part by the UK National Institute for Health Research (NIHR) Leeds Biomedical Research Centre. The views expressed in this publication are those of the author(s) and not necessarily those of the National Health Service, the NIHR or the Department of Health. The authors would like to express their most sincere gratitude to Dr Lisa Buttle for her invaluable help with the manuscript preparation. Dr Lisa Buttle was entirely funded by the ESCEO asbl, Belgium.

\section{Compliance with Ethical Standards}

The authors meet the International Committee of Medical Journal Editors (ICMJE) criteria for authorship for this manuscript, take responsibility for the integrity of the work as a whole, and have given final approval of the version to be published.

Role of the Funding Source The ESCEO Working Group was entirely funded by the ESCEO, a Belgian not-for-profit organization that receives unrestricted educational grants, to support its educational and scientific activities, from non-governmental organizations, notfor-profit organizations, and non-commercial and corporate partners. The choice of topics, participants, content and agenda of the working groups, as well as the writing, editing, submission and reviewing of the manuscript, are under the sole responsibility of the ESCEO, without any influence from third parties.

Conflict of interest Philip G. Conaghan reports consultancy fees or speakers' bureau fees from Abbvie, BMS, Flexion Therapeutics, GlaxoSmithKline, Merck Serono, Novartis, Pfizer, Roche and Samumed outside of the submitted work. Nigel Arden reports personal fees from Bioventus, Flexion, Merck, Pfizer/Lilly, Regeneron, Smith \& Nephew and Freshfields Bruckhaus Deringer, as well as grants from Bioiberica and Merck, outside of the submitted work. Alberto Migliore reports fees for participation in review activities from Fidia, MSD, Sanofi and Novartis, and payment for lectures from Roche, GUNA, Ibsa, Abiogen and Pfizer, outside of the submitted work.

Open Access This article is distributed under the terms of the Creative Commons Attribution-NonCommercial 4.0 International License (http://creativecommons.org/licenses/by-nc/4.0/), which permits any noncommercial use, distribution, and reproduction in any medium, provided you give appropriate credit to the original author(s) and the source, provide a link to the Creative Commons license, and indicate if changes were made.

\section{References}

1. Woolf AD, Pfleger B. Burden of major musculoskeletal conditions. Bull World Health Organ. 2003;81(9):646-56.

2. Kluzek S, Sanchez-Santos MT, Leyland KM, Judge A, Spector TD, Hart D, et al. Painful knee but not hand osteoarthritis is an independent predictor of mortality over 23 years follow-up of a population-based cohort of middle-aged women. Ann Rheum Dis. 2016;75(10):1749-56.

3. Vos T, Flaxman AD, Naghavi M, Lozano R, Michaud C, Ezzati M, et al. Years lived with disability (YLDs) for 1160 sequelae of 289 diseases and injuries 1990-2010: a systematic analysis for the Global Burden of Disease Study 2010. Lancet. 2012;380(9859):2163-96. 
4. Jóźwiak-Bebenista M, Nowak JZ. Paracetamol: mechanism of action, applications and safety concern. Acta Pol Pharm. 2014;71(1):11-23.

5. World Health Organization. World Health Organization Model List of Essential Medicines. 2017. http://www.who.int/medicines/ publications/essentialmedicines/en/. Accessed 6 Feb 2018.

6. Bruyere O, Cooper C, Pelletier JP, Branco J, Brandi ML, Guillemin $\mathrm{F}$, et al. An algorithm recommendation for the management of knee osteoarthritis in Europe and internationally: a report from a task force of the European Society for Clinical and Economic Aspects of Osteoporosis and Osteoarthritis (ESCEO). Semin Arthritis Rheum. 2014;44(3):253-63.

7. McAlindon TE, Bannuru RR, Sullivan MC, Arden NK, Berenbaum F, Bierma-Zeinstra SM, et al. OARSI guidelines for the non-surgical management of knee osteoarthritis. Osteoarthritis Cartil. 2014;22(3):363-88.

8. Hochberg MC, Altman RD, April KT, Benkhalti M, Guyatt G, McGowan J, et al. American College of Rheumatology 2012 recommendations for the use of nonpharmacologic and pharmacologic therapies in osteoarthritis of the hand, hip, and knee. Arthritis Care \& Res. 2012;64(4):465-74.

9. National Institute for Health and Care Excellence. Osteoarthritis care and management in adults: Methods, evidence and recommendations. Report No.: CG177. London: National Clinical Guideline Centre, National Institute for Health and Care Excellence; Feb 2014.

10. Blieden M, Paramore LC, Shah D, Ben-Joseph R. A perspective on the epidemiology of acetaminophen exposure and toxicity in the United States. Expert Rev Clin Pharmacol. 2014;7(3):341-8.

11. McLachlan AJ, Bath S, Naganathan V, Hilmer SN, Le Couteur DG, Gibson SJ, et al. Clinical pharmacology of analgesic medicines in older people: impact of frailty and cognitive impairment. Br J Clin Pharmacol. 2011;71(3):351-64.

12. Rochon PA, Fortin PR, Dear KBG, Minaker KL, Chalmers TC. Reporting of age data in clinical trials of arthritis: deficiencies and solutions. Arch Intern Med. 1993;153(2):243-8.

13. Kingsbury SR, Hensor EM, Walsh CA, Hochberg MC, Conaghan PG. How do people with knee osteoarthritis use osteoarthritis pain medications and does this change over time? Data from the Osteoarthritis Initiative. Arthritis Res Ther. 2013;15(5):R106.

14. Kingsbury SR, Gross HJ, Isherwood G, Conaghan PG. Osteoarthritis in Europe: impact on health status, work productivity and use of pharmacotherapies in five European countries. Rheumatology. 2014;53(5):937-47.

15. Cheve H, Marinthe AC, Lelong-Boulouard V, Lescure P, Guillaume C. Status report of analgesic prescriptions by general practitioners in elderly people aged 75 and over, upon admission in geriatric medicine. Geriatrie et psychologie neuropsychiatrie du vieillissement. 2018;16(2):133-44.

16. Conaghan PG, Peloso PM, Everett SV, Rajagopalan S, Black CM, Mavros $\mathrm{P}$, et al. Inadequate pain relief and large functional loss among patients with knee osteoarthritis: evidence from a prospective multinational longitudinal study of osteoarthritis real-world therapies. Rheumatology. 2015;54(2):270-7.

17. Raja R, Dube B, Hensor EM, Hogg SF, Conaghan PG, Kingsbury SR. The clinical characteristics of older people with chronic multiple-site joint pains and their utilisation of therapeutic interventions: data from a prospective cohort study. BMC Musculoskel Disorders. 2016;17:194.

18. Towheed TE, Maxwell L, Judd MG, Catton M, Hochberg MC, Wells G. Acetaminophen for osteoarthritis. The Cochrane database of systematic reviews. 2006;(1):CD004257.

19. Zhang W, Nuki G, Moskowitz RW, Abramson S, Altman RD, Arden NK, et al. OARSI recommendations for the management of hip and knee osteoarthritis: part III: Changes in evidence following systematic cumulative update of research published through January 2009. Osteoarthritis Cartil. 2010;18(4):476-99.

20. Machado GC, Maher CG, Ferreira PH, Pinheiro MB, Lin CW, Day $\mathrm{RO}$, et al. Efficacy and safety of paracetamol for spinal pain and osteoarthritis: systematic review and meta-analysis of randomised placebo controlled trials. BMJ. 2015;350:h1225.

21. da Costa BR, Reichenbach S, Keller N, Nartey L, Wandel S, Juni $\mathrm{P}$, et al. Effectiveness of non-steroidal anti-inflammatory drugs for the treatment of pain in knee and hip osteoarthritis: a network meta-analysis. Lancet. 2017;390(10090):e21-33.

22. Gregori D, Giacovelli G, Minto C, Barbetta B, Gualtieri F, Azzolina $\mathrm{D}$, et al. Association of pharmacological treatments with long-term pain control in patients with knee osteoarthritis: a systematic review and meta-analysis. JAMA. 2018;320(24):2564-79.

23. Williams HJ, Ward JR, Egger MJ, Neuner R, Brooks RH, Clegg $\mathrm{DO}$, et al. Comparison of naproxen and acetaminophen in a twoyear study of treatment of osteoarthritis of the knee. Arthritis Rheum. 1993;36(9):1196-206.

24. Roberts E, Delgado Nunes V, Buckner S, Latchem S, Constanti M, Miller P, et al. Paracetamol: not as safe as we thought? A systematic literature review of observational studies. Ann Rheum Dis. 2016;75(3):552-9.

25. de Vries F, Setakis E, van Staa TP. Concomitant use of ibuprofen and paracetamol and the risk of major clinical safety outcomes. Br J Clin Pharmacol. 2010;70(3):429-38.

26. Lipworth L, Friis S, Mellemkjaer L, Signorello LB, Johnsen SP, Nielsen GL, et al. A population-based cohort study of mortality among adults prescribed paracetamol in Denmark. J Clin Epidemiol. 2003;56(8):796-801.

27. Curhan GC, Knight EL, Rosner B, Hankinson SE, Stampfer MJ. Lifetime nonnarcotic analgesic use and decline in renal function in women. Arch Intern Med. 2004;164(14):1519-24.

28. Gualtierotti R, Zoppi A, Mugellini A, Derosa G, D’Angelo A, Fogari R. Effect of naproxen and acetaminophen on blood pressure lowering by ramipril, valsartan and aliskiren in hypertensive patients. Expert Opin Pharmacother. 2013;14(14):1875-84.

29. de Abajo FJ, Gil MJ, Garcia Poza P, Bryant V, Oliva B, Timoner J, et al. Risk of nonfatal acute myocardial infarction associated with non-steroidal antiinflammatory drugs, non-narcotic analgesics and other drugs used in osteoarthritis: a nested case-control study. Pharmacoepidemiol Drug Saf. 2014;23(11):1128-38.

30. Garcia-Poza P, de Abajo FJ, Gil MJ, Chacon A, Bryant V, GarciaRodriguez LA. Risk of ischemic stroke associated with non-steroidal anti-inflammatory drugs and paracetamol: a population-based case-control study. J Thromb Haemost. 2015;13(5):708-18.

31. Boureau F, Schneid H, Zeghari N, Wall R, Bourgeois P. The IPSO study: ibuprofen, paracetamol study in osteoarthritis. A randomised comparative clinical study comparing the efficacy and safety of ibuprofen and paracetamol analgesic treatment of osteoarthritis of the knee or hip. Ann Rheum Dis. 2004;63(9):1028-34.

32. Moore N, Ganse EV, Parc J-ML, Wall R, Schneid H, Farhan M, et al. The PAIN study: paracetamol, aspirin and ibuprofen new tolerability Study. Clin Drug Investig. 1999;18(2):89-98.

33. Rampal P, Moore N, Van Ganse E, Le Parc JM, Wall R, Schneid $\mathrm{H}$, et al. Gastrointestinal tolerability of ibuprofen compared with paracetamol and aspirin at over-the-counter doses. J Int Med Res. 2002;30(3):301-8.

34. Garcia Rodriguez LA, Hernandez-Diaz S. Risk of uncomplicated peptic ulcer among users of aspirin and nonaspirin nonsteroidal antiinflammatory drugs. Am J Epidemiol. 2004;159(1):23-31.

35. Garcia Rodriguez LA, Hernandez-Diaz S. The risk of upper gastrointestinal complications associated with nonsteroidal antiinflammatory drugs, glucocorticoids, acetaminophen, and combinations of these agents. Arthritis Res. 2001;3(2):98-101.

36. Rahme E, Barkun A, Nedjar H, Gaugris S, Watson D. Hospitalizations for upper and lower GI events associated with traditional 
NSAIDs and acetaminophen among the elderly in Quebec, Canada. Am J Gastroenterol. 2008;103(4):872-82.

37. O'Neil CK, Hanlon JT, Marcum ZA. Adverse effects of analgesics commonly used by older adults with osteoarthritis: focus on non-opioid and opioid analgesics. Am J Geriatr Pharmacother. 2012;10(6):331-42.

38. Jaeschke H. Acetaminophen: dose-dependent drug hepatotoxicity and acute liver failure in patients. Dig Dis. 2015;33(4):464-71.

39. Wynne HA, Cope LH, Herd B, Rawlins MD, James OF, Woodhouse KW. The association of age and frailty with paracetamol conjugation in man. Age Ageing. 1990;19(6):419-24.

40. Gulmez SE, Larrey D, Pageaux GP, Bernuau J, Bissoli F, Horsmans $Y$, et al. Liver transplant associated with paracetamol overdose: results from the seven-country SALT study. Br J Clin Pharmacol. 2015;80(3):599-606.

41. Craig DG, Bates CM, Davidson JS, Martin KG, Hayes PC, Simpson KJ. Staggered overdose pattern and delay to hospital presentation are associated with adverse outcomes following paracetamolinduced hepatotoxicity. Br J Clin Pharmacol. 2012;73(2):285-94.

42. Chan AT, Manson JE, Albert CM, Chae CU, Rexrode KM, Curhan GC, et al. Nonsteroidal antiinflammatory drugs, acetaminophen, and the risk of cardiovascular events. Circulation. 2006;113(12):1578-87. https://doi.org/10.1161/circulatio naha.105.595793. 